Bestandtheile vorkommen, so muss dic Beimengung des Sandes resp. des Schwefelarseniks auf Zufalligkeiten beruhen. Der Schellack wird in Siam, Laos, Assam, Pegu, Sumatra und Bengalen gewonnen, wo durch die herrschenden Winde der Flugsand leicht auf den noch im weichen Zustande befindlichen Körnerlack geführt werden kann. Dieser Sand muss also Schwefelarsenik enthalten. Biichner sucht mit hierin einen Grund der Gefahrlichkeil des dortigen Klimas. (?) Die Kingebornen seien bis zu einem gewissen Grade daran gewóhnt und dagegen unempfindlich; jedoch muissen sie auch of dem gelben Fieber, welches in den Symptomen einer Arsenikvergiftung gleiche, unterliegen. (Amal. der Chemie u. Pharm. Bd. 59 . p. 96-101.)

$\mathrm{Hz}$.

\title{
Einwirkung der Ipecacuanha auf Tartarus stibiatus.
}

Apotheker Gartner in Hanau wollte bcobachtel haben, dass die Ipecacuanha, wenn sie mil Brechweinstein in Berührung komme, die Natur dieses Salzes dahin abändere, dass das Spiessglanzoxyd in derselben von der Hahnemannschen Probe nicht mehr mit der Farbe des Goldschwefels, sondern mil der des Eidotters niedergeschlagen werde. Dr. E. Riegel prifte diese Angabe und fand, dass dic Brechwurzel keinen zersetzenden Einfluss auf den Brechweinstein ausübt und dass dio milunter sich zeigende seltene Färbung des durch Schwefelwasserstoffgas entstandenen Niederschlags durch das längere Suspendirtsein erklärt werden duirfe (?) (Jahrb. f. prakt. Pharm. 14. 1. 47.)

B.

\section{Bereitung des Extr. Radic. Liquiritiae.}

Ma yer in Heilbronn stellte einige vergleichende Versuche an uiber die Bereitungsweise der neuen würtembergischen Pharmakopöe und der mittelst der Realschen Presse. Nach der erstern erhielt er aus 8 Pfd. Süssholz

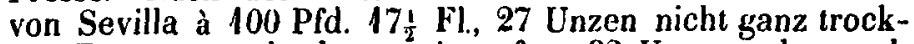
nes Extract, nach der zweiten fast 32 Unzen; das nach der erstern Methode erhaltene besass einen mildern und rein suissen Geschmack, das nach der andern einen mehr kratzenden bitterlichen. (Jahrb. f. pralit. Pharm. 14.1.32.) 